\title{
Pilot initiatives of adult hearing screening in Italy
}

\author{
A. Paglialonga, G. Tognola, F. Grandori \\ CNR - Consiglio Nazionale delle Ricerche, Istituto di Ingegneria Biomedica (IsIB), Milan, Italy
}

\begin{abstract}
A series of pilot initiatives of adult hearing screening programs were organized in eight large and small-size cities in Italy in the past two years. The screening initiatives were held in public places, supermarkets, drugstores, and in some universities of the third age, and involved an overall population of 2,278 screened subjects with age ranging from 13 to 93 years. Three different screening tests were used to assess hearing ability in the participants, i.e.: screening pure tone audiometry (PTA), an automated speech-in-noise screening test (the SUN-test), and a screening questionnaire of self-perceived hearing handicap (the HHIE-S). This paper describes the organization and management of these screening initiatives and reviews the main results obtained in the screened population, using the three different screening tests. Results obtained in these pilot initiatives showed that screening adults for hearing problems might be feasible, on a local level, in non clinical settings and can be performed quite easily with the support of local coordinators and partners, such as associations or local authorities. It is recognized that further initiatives and studies will have to be performed to better define the key aspects related to the organization and management of adult hearing screening programs, either at a local, regional, or national level.
\end{abstract}

Correspondence: A. Paglialonga, Istituto di Ingegneria Biomedica (IsIB), Consiglio Nazionale delle Ricerche, c/o Politecnico di Milano, piazza Leonardo da Vinci, 3220133 Milan, Italy.

Tel. +39.02.23993343 - Fax: +39.02 .23993367 .

E-mail: alessia.paglialonga@polimi.it

Key words: hearing screening, adults, elderly, hearing impairment, hearing handicap, hearing disability.

Acknowledgements: This work was performed in the framework of the European project "AHEAD III: Assessment of Hearing in the Elderly: Aging and Degeneration - Integration through Immediate Intervention" (20082011) (FP7, contract No. HEALTH-F2-2008-200835). The Authors are grateful to the Lions Clubs International in Italy for their invaluable support in the organization, promotion, and management of the hearing screening initiatives in the cities of Bologna, Brugherio, Castellanza, Cinisello Balsamo, Lainate, Milano, Segrate, and Sesto San Giovanni.

(C) Copyright A. Paglialonga et al., 2011

Licensee PAGEPress, Italy

Audiology Research 2011; 1:e17

doi:10.4081/audiores.2011.e17

This article is distributed under the terms of the Creative Commons Attribution Noncommercial License (by-nc 3.0) which permits any noncommercial use, distribution, and reproduction in any medium, provided the original author(s) and source are credited.

Parts of this work were presented at the "AHS 2010 - International Conference on Adult Hearing Screening”, Cernobbio (Italy), June 10-12, 2010.

\section{Introduction}

Hearing loss is a relevant and increasingly spread psychosocial problem, with significant implications in terms of isolation, distress, depression, and loneliness, and can severely impair quality of life in the adult population (Danermark et al., 2010; Nachtegaal et al, 2009). Adults and older adults may not realize that they have a hearing problem because it is relatively mild, or slowly progressive, and when they perceive that they have a hearing impairment, they may not promptly seek evaluation for it, or they may have difficulty recognizing or reporting hearing problems. It is estimated that only $10 \%$ to $20 \%$ of older adults with hearing loss have ever used hearing aids (Popelka et al., 1998).

Screening could identify untreated hearing loss in people who could benefit from treatment. Increasing evidence indicates that screening, together with early intervention, has the potential to significantly improve hearing-related function and quality of life in adults and older adults (Chou et al., 2011; Liu et al., 2011; Yueh et al., 2010).

Remarkably, a number of initiatives in the few past years have promoted the definition of accessible programs of hearing screening and hearing care in adults, both in the US (Chou et al., 2011; Donahue et al., 2010) and in Europe (Davis et al., 2007; Grandori et al., 2009), and some medium and large scale pilot programs of adult hearing screening have been established, e.g. in the United Kingdom (Davis et al., 2007), the Netherlands (Smits \& Houtgast, 2005), Poland (Sułkowski et al., 2001), or Cyprus (Thodi et al., 2011).

This paper will report on a series of pilot initiatives of adult hearing screening that were organized in a period of two years in eight cities in Italy, where an overall population of nearly 2,300 adults and older adults were screened. The organization and management of these initiatives will be described, the main results obtained in the tested population, using different screening tests, will be reviewed, and the feasibility of implementing hearing screening programs in the adult population will be discussed.

\section{Methods}

A series of pilot initiatives of adult hearing screening were organized in a period of two years (March 2009- March 2011) in Milano and in other seven large and small cities in Italy, involving an overall population of nearly 2,300 adults and older adults.

The initiatives were organized by the Institute of Biomedical Engineering of the Italian National Research Council (IsIB-CNR), that acted as central coordinator, with the collaboration of the Lions Clubs International, whose members played as local coordinators in the different screening sites. Screening was performed in public places, supermarkets, drugstores, and in some universities of the third age. Hearing screening was provided for a period that varied from one up to six weeks across the different sites, depending on the 
expected number of participants. The initiatives were promoted with public announcements on local newspapers, advertisements on local broadcasting networks, posters and flyers distributed in pharmacies, supermarkets, and other public places. In each site, the local coordinators organized preliminary informative meetings with the population where participants were informed of the screening initiatives and received explanatory brochures with information about the initiatives and details of the local contact person(s).

Screening was performed by clinical staff or by volunteers with proven track record in audiometric testing. Data were recorded anonymously by assigning a unique ID to each participant; personal details of participants (name, surname and contact details) were used only by the local coordinators for the unique purpose of setting the appointments.

Overall, three screening tests were used throughout the different initiatives:

i) PTA: air conduction pure-tone audiometry at 1, 2, and $4 \mathrm{kHz}$, in both ears. Based on the PTA thresholds at the tested frequencies, the test outcome was set as: PTA Class I if thresholds were better than $40 \mathrm{~dB}$ HL at all the tested frequencies; PTA Class II if thresholds were better than $40 \mathrm{~dB}$ HL at 1 and $2 \mathrm{kHz}$ but higher than $40 \mathrm{~dB}$ HL at $4 \mathrm{kHz}$; or PTA Class III if thresholds were higher than $40 \mathrm{~dB} \mathrm{HL}$ both at 2 and at $4 \mathrm{kHz}^{*}$;

ii) SUN-test: an automated speech-in-noise test recently developed to screen adults and older adults for hearing disability (Grandori $e t$ al., 2010; Paglialonga et al., 2011). The SUN-test in the Italian language is composed of a list of 12 intervocalic consonants in noise, presented in a three-alternatives forced-choice (3AFC) task by means of a touch-screen interface. Based on the number of stimuli correctly identified by the subject, the test outcome was set as: no listening difficulties (9 or more correct responses), a hearing check would be advisable (7 or 8 correct responses), or a hearing check is recommended (6 or less correct responses);

iii) HHIE-S (Hearing Handicap for the Elderly - Screening): a 10 items questionnaire that assesses the emotional and soci al consequences of hearing impairment. Based on the questionnaire score, which can range from 0 to 40 , the test outcome was set as: no handicap (score $\leq 8$ ), mild-to-moderate handicap (score in the range 1022 ), or severe handicap (score $\geq 24$ ) (Ventry \& Weinstein, 1983). The Italian version of the questionnaire was used, as can be found in Giordano et al. (2008).

All the screened subjects were tested by using a combination of $a t$ least two of these three screening tests (typically, the PTA and the SUN-test, or the HHIE-S and the SUN-test); in some cities, subjects were screened by using all the three tests.

\section{Results}

An overall population of 2,278 subjects were screened (911 male, 1,367 female). The age distribution in the screened population is shown in Figure 1. The mean age in the tested population was 59.5 years (s.d. 16 years, range 13-93 years). The majority of the screened subjects (i.e., nearly 1,400) were between 56 and 75 years old, but there was also a relatively large proportion of subjects younger than 50 years participating to the screening, mostly during the initiatives held in public places, supermarkets, or drugstores.

\footnotetext{
* The cut-off value of $40 \mathrm{~dB}$ HL was set following the suggestions by Ventry \& Weinstein (1983) for adult hearing screening, also in line with the definition of 'disabling hearing impairment' given by the World Health Organization (2008) and the threshold used by the Veterans Health Administration to define hearing loss (US Congress, 1987).
}

All the screened subjects were asked whether they had already checked their hearing before the screening and, also, to report the reason why they chose to participate to the screening initiatives. Results of this survey are shown in Figure 2.

Of all the participants, $68 \%$ reported never having tested their hearing before the screening, $17 \%$ reported having been previously tested within surveillance programs at their workplaces, or opportunistically elsewhere (e.g., pharmacies, local campaigns, hearing aid providers), and $14 \%$ reported having had an audiological examination at least once prior to the screening; only a minor proportion (i.e., 1\%) did not remember or was not sure. As to the reasons for their participation to the screening, nearly half (i.e., 46\%) of subjects believed they had to check their hearing; nearly a quarter (i.e., 27\%) had been advised by others to do a hearing check, and nearly a fifth (i.e., 19\%) participated for curiosity, to check whether they had any hearing problem or not.

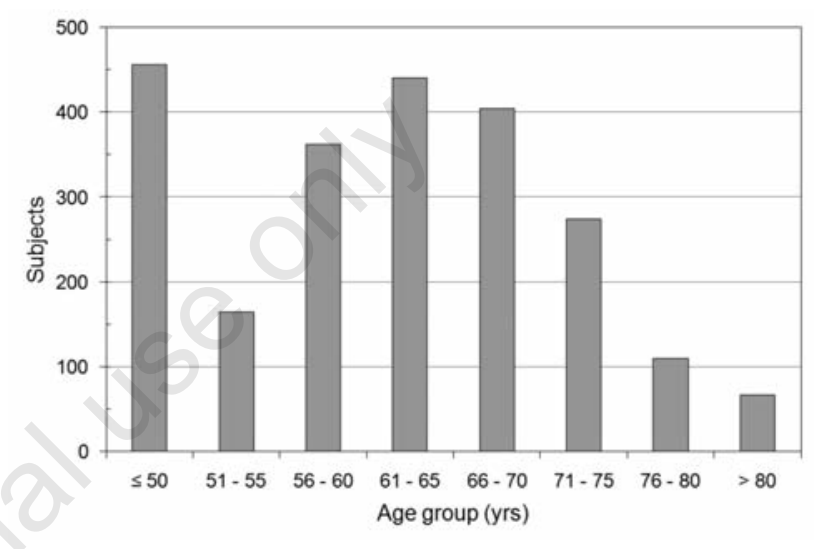

Figure 1. Age distribution in the overall screened population $(\mathrm{N}=$ 2,278 subjects).

\section{Have you ever checked your hearing?}

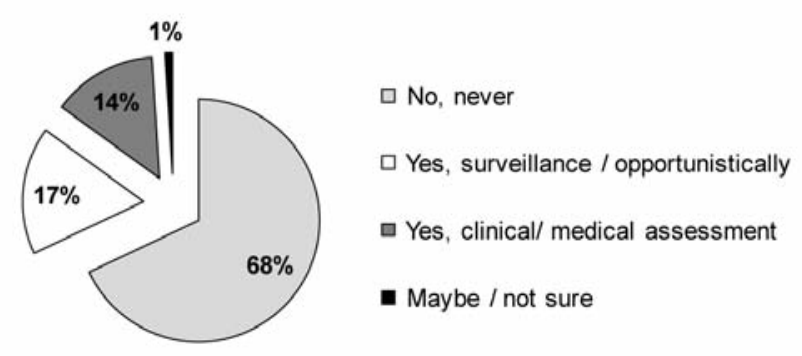

Why are you participating?

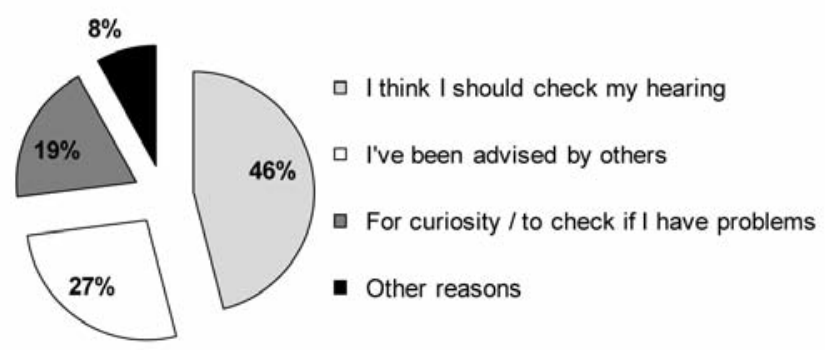

Figure 2. Distribution of the answers given by the screened subjects to the two questions Have you ever checked your hearing?' and 'Why are you participating?' $(\mathrm{N}=2,278$ subjects). 
A population of 1,410 subjects out of the 2,278 screened were tested with pure tone audiometry (PTA). Of these 1,410 subjects, 101 had a hearing aid and were thus tested only in the unaided ear, whereas in the remaining 1,309 subjects both ears were screened, for a total of 2,719 ears tested. The mean time needed to perform PTA was nearly 2 minutes per ear, so that testing both ears required less than 5 minutes. In some subjects, particularly the older ones or those with poor hearing thresholds, measuring PTA required a longer time, up to 10 minutes to test both ears. Table 1 shows the distribution of PTA outcomes in the 2,719 tested ears. Overall, nearly $78 \%$ of ears were in PTA Class I (i.e., pure tone thresholds better than $40 \mathrm{~dB}$ HL at each of the tested frequencies), nearly $15 \%$ of ears were in PTA Class II (i.e., threshold higher than $40 \mathrm{~dB}$ HL only at $4 \mathrm{kHz}$ ), and the remaining $7 \%$ were in PTA Class III (i.e., thresholds higher than $40 \mathrm{~dB}$ HL both at 2 and at $4 \mathrm{kHz}$ ).

The distribution of PTA outcomes as a function of age in the screened population is shown in Figure 3. It could be observed that PTA steadily worsened with increasing age, as can be expected in the adult population, in line with data reported in the literature (see, e.g., Cruickshanks et al., 1998; 2010; Gates et al., 2008). As the age increased, the percentage of ears classified in PTA Class I decreased from about $95 \%$ in subjects younger than 50 years to nearly $30 \%$ in subjects aged 80 years or older. Dually, the overall percentage of ears either in Class II or III increased from a negligible 5\% in subjects younger than 50 years to nearly $70 \%$ in subjects older than 80 years. It could also be observed that in the oldest age group the proportion of ears in PTA Class III (i.e., 43\%) was higher than the proportion of ears in Class II (i.e., 37\%), indicating a higher prevalence of hearing loss at the mid to low frequencies compared to hearing loss only at 4 $\mathrm{kHz}$ in subjects older than 80 years.

All the 2,275 screened subjects were tested with the SUN-test. 111 subjects had a hearing aid and were thus tested only in the unaided ear, whereas the remaining 2,164 subjects performed the SUN test in both ears, for a total of 4,439 ears tested. The mean time needed to

Table 1. Distribution of PTA outcomes in the screened population ( $\mathrm{N}=2,719$ ears).

\begin{tabular}{lc} 
PTA outcome & N. of ears \\
CLASS I & $2109 / 2719(77.6 \%)$ \\
CLASS II & $418 / 2719(15.4 \%)$ \\
\hline CLASS III & $192 / 2719(7.0 \%)$ \\
\hline
\end{tabular}

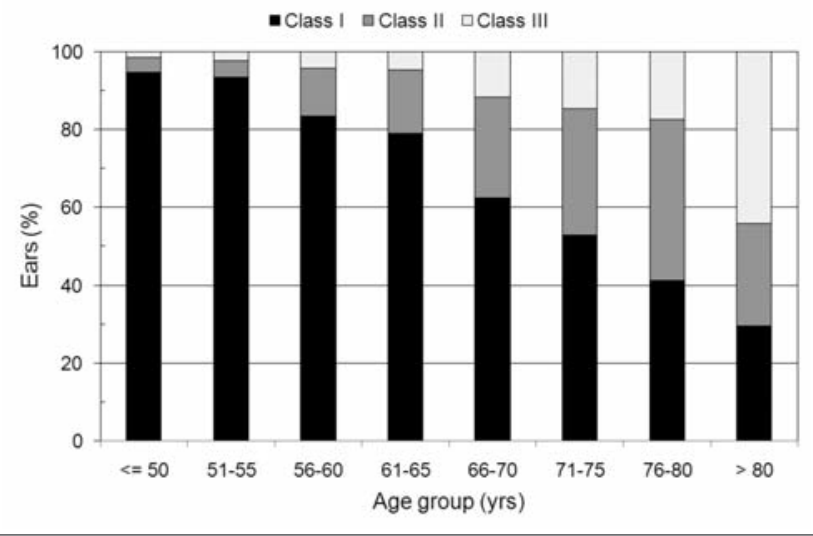

Figure 3. Distribution of PTA outcomes as a function of age in the screened population ( $\mathrm{N}=2,719$ ears). complete the SUN test was less than 1 minute per ear, so that testing both ears required, on average, 2 minutes. Test time was lower than 3 minutes for both ears even in the older subjects. Table 2 shows the distribution of SUN test outcomes in the 4,439 tested ears. Overall, nearly $54 \%$ of ears had no listening difficulties, in nearly $30 \%$ of ears a hearing check was advised, and in nearly $17 \%$ a hearing check was recommended.

Figure 4 shows the distribution of the SUN test outcomes as a function of age in the screened population. As previously observed about PTA outcomes, the SUN-test outcomes worsened with increasing age, as well. The proportion of ears with no listening difficulties (score $\geq 9$ ) decreased from about $68 \%$ in subjects younger than 50 years to nearly $17 \%$ in subjects aged 80 years or older. Vice versa, the proportion of ears that had a hearing check is recommended as test outcome (score $\leq 6$ ) was nearly $10 \%$ in subjects younger than 65 years but increased to more than $50 \%$ in subjects older than 80 years. The proportion of ears that obtained a hearing check would be advisable as test outcome (score $=7$ or 8 ) was almost the same through the different age groups (i.e., nearly $30 \%$ both in younger and in older subjects).

The HHIE-S was administered to 1,902 of the 2,275 screened subjects. On average, the questionnaire took nearly 5 minutes to be filled in, though in some of the older subjects the time required increased up to 10 minutes. Table 3 shows the distribution of HHIE-S outcomes in the 1,902 subjects that were screened with the questionnaire. Nearly $68 \%$ of subjects reported no self perceived handicap, nearly $28 \%$ reported a mild to moderate handicap, and only a minor proportion (i.e., 4\%) reported a significant handicap.

The distribution of the HHIE-S outcomes as a function of age in the screened population is shown in Figure 5. The HHIE-S outcomes exhibited quite a similar trend as PTA and the SUN-test outcomes, i.e. they tended to worsen with increasing age. The proportion of subjects reporting no self perceived hearing handicap (questionnaire score $\leq 8$ ) was nearly $80 \%$ in the youngest age group, decreased to $60-70 \%$

Table 2. Distribution of SUN-test outcomes in the screened population $(\mathrm{N}=4,439$ ears).

\begin{tabular}{lc} 
SUN-test outcome & N. of ears \\
No listening difficulties & $2378 / 4439(53.6 \%)$ \\
A hearing check would be advisable & $1324 / 4439(29.8 \%)$ \\
\hline A hearing check is recommended & $737 / 4439(16.6 \%)$ \\
\hline
\end{tabular}

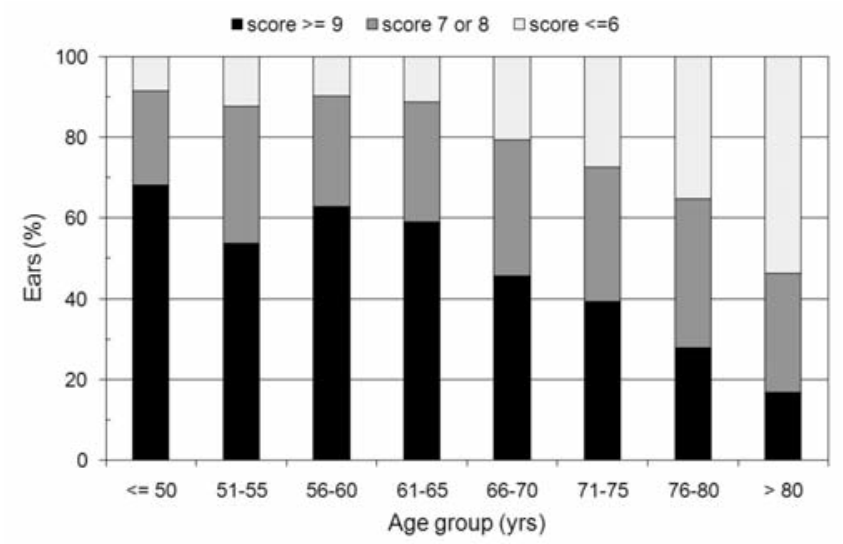

Figure 4. Distribution of SUN-test outcomes as a function of age in the screened population ( $\mathrm{N}=4,439$ ears). 
in subjects between 60 and 80 years old, and to nearly $36 \%$ in subjects older than 80 years. The proportion of subjects reporting severe hearing handicap (questionnaire score $\geq 24$ ) was between $2 \%$ and $5 \%$ in most age groups, and increased to more than $15 \%$ only in subjects aged 80 years or more. The prevalence of mild-to-moderate handicap tended to increase, as well, from nearly $12 \%$ in the youngest subjects to slightly less than $50 \%$ in the oldest age group.

\section{Discussion and Conclusions}

A series of pilot initiatives of adult hearing screening were organized in a period of two years in eight large and small-size cities in Italy. The screening initiatives were held in public places, supermarkets, drugstores, and in some universities of the third age, and lasted from one up to six weeks each. Overall, a population of 2,278 adults and older adults were screened (911 male, 1,367 female).

Three different screening tests were used to assess hearing ability in the participants, i.e.: screening pure-tone audiometry (PTA), a speech-in-noise screening test (the SUN-test), and a screening questionnaire of self-perceived hearing handicap (the HHIE-S). Typically, a combination of two of these tests was used (the PTA and the SUNtest, or the HHIE-S and the SUN-test); in some initiatives, all the three screening tests were used. Based on the outcomes of the screening tests, those subjects who were found to have hearing problems were referred for further audiological assessment.

Because the three screening tests assess different domains of hearing functionality, a combination of different tests allows, in principle, to more precisely assess possible hearing problems: PTA allows to detect possible declines in hearing sensitivity; the SUN-test allows to measure the ability to understand speech in challenging listening situations and can, as such, effectively target the real experienced listening difficulties in adults; and the HHIE-S reflects the handicap perceived by the hearing impaired subject. Results obtained with each of the three tests in the overall screened population indicated

Table 3. Distribution of HHIE-S outcomes in the screened population ( $\mathrm{N}=1,902$ subjects).

\begin{tabular}{lc} 
HHIIE-S outcome & N. of subjects \\
No handicap & $1292 / 1902(67.9 \%)$ \\
Mild-to-moderate handicap & $531 / 1902(27.9 \%)$ \\
\hline Significant handicap & $79 / 1902(4.2 \%)$ \\
\hline
\end{tabular}

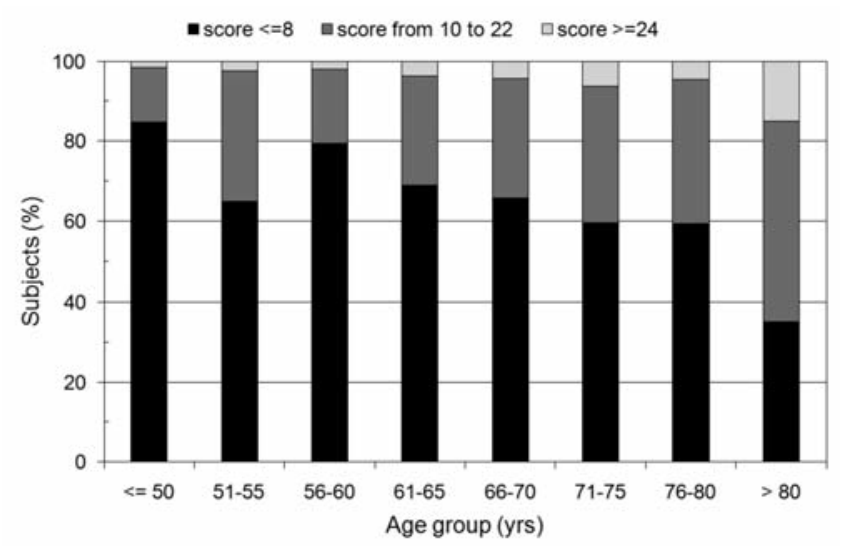

Figure 5. Distribution of the HHIE-S outcomes as a function of age in the screened population ( $\mathrm{N}=1,902$ subjects). that test outcomes steadily tended to worsen as the age of the tested subjects increased (see Figures 3-5). This is fully in line with data from literature (see, e.g., Cruickshanks et al., 1998; 2010; Gates et al., 2008) that widely document how the prevalence of hearing problems increases with age, due to declines both in hearing sensitivity, central auditory processing, and cognitive performance that typically occur in adults with increasing age (Divenyi et al., 2005; Pichora Fuller \& Singh, 2006; Schneider et al., 2010).

The duration of the whole screening session was less than 10 minutes per subject when two tests were combined and, on average, less than 15 minutes when all the three screening tests were used. Thanks to the limited test time, an average of nearly 150 subjects could be screened every week and, in the biggest cities, up to 250 subjects per week. Results of the survey among the participants (see Figure 2) revealed that most subjects had never checked their hearing before the screening, and that nearly $15 \%$ had a hearing check opportunistically or because of surveillance programs (for example, at their workplace); at the same time, most subjects felt the need to have their hearing checked, either because they believed they had hearing problems ( $46 \%$ of subjects), or because their relatives or friends told them that they probably had hearing problems $(27 \%$ of subjects). These data confirm that, often, people who actually have hearing problems, or simply doubt their hearing, might pay no attention to this and not seek evaluation for their hearing; yet, screening initiatives like those here described allow these people to easily have their hearing checked, and to become aware of the need to monitor their hearing as they become older.

To sum up, our experience with these pilot initiatives shows that screening adults for hearing problems might be feasible in non clinical settings on a local level, and can be performed quite easily with the support of local coordinators and partners, such as associations or local authorities. However, it is still very important that more effort will be spent in this direction in order to better understand the key aspects related to the organization and management of adult hearing screening programs, and that further pilot initiatives will be organized to better define a possible roadmap to implement adult hearing screening either on a local, regional, or national level.

\section{References}

Chou R., Dana T., Bougatsos C., Fleming C., and Beil T. 2011. Screening adults aged 50 years or older for hearing loss: A review of the evidence for the U.S. Preventive Services Task Force. Annals of Internal Medicine, 154, 347-355.

Cruickshanks, K.J., Zhan, W., Zhong, W. 2010. Epidemiology of AgeRelated Hearing Impairment. In: Gordon-Salant, S., Frisina, R.D., Popper, A.N., Fay, R.R. (eds.) The aging auditory system. Springer, New York, USA, 259-275.

Cruickshanks, K.J, Wiley, T., Tweed, T. 1998. Prevalence of hearing loss in older adults in Beaver Dam, Wisconsin: The epidemiology of hearing loss study. Am J Epidemiol 148:879-886.

Danermark, B., Cieza, A., Gangé, JP., Gimigliano, F., Granberg, S., Hickson, L., Kramer, SE., McPherson, B., Möller, C., Russo, I., Strömgren, JP., Stucki, G., Swanepoel, D. 2010. International classification of functioning, disability, and health core sets for hearing loss: A discussion paper and invitation. Int J Audiol 49:256262 .

Davis, A., Smith, P., Ferguson, M., Stephens, D., Gianopoulos, I. 2007. Acceptability, benefit and costs of early screening for hearing disability: a study of potential screening tests and models. Health Technology Assessment 11:1-294.

Divenyi, P.L,. Stark, P.B., Haupt, K.M. 2005. Decline of speech under- 
standing and auditory thresholds in the elderly. J Acoust Soc Am 118:1089-1100.

Donahue, A., Dubno, J.R., Beck, L. 2010. Guest editorial: accessible and affordable hearing health care for adults with mild to moderate hearing loss. Ear Hear 31:2-6.

Gates, G.A., Feeney, M.P. Mills, D.M. 2008. Cross-sectional age changes of hearing in the elderly. Ear Hear 29:865-874.

Giordano, C., Garzaro, M., Canovi, C. 2008. Questionari per protesi acustiche. In: Vitale S. (ed.) Refertazione e interpretazione dei tracciati e dei questionari in ORL. Quaderni Monografici di Aggiornamento- Associazione Otorinolaringologi Ospedalieri Italiani. Lecce, 133-148.

Grandori, F., Tognola, G., Paglialonga, A. 2010. A new test for screening hearing ability in adults. In Proc. International Conference on Adult Hearing Screening - AHS2010, Cernobbio (Italy), June 1012, 2010.

Grandori, F., Parazzini, M., Tognola, G., Paglialonga, A. 2009. Hearing screening in older adults is gaining momentum - The European project AHEAD III on adult hearing. In: Hickson L. (ed.) Proceedings of the 2nd Phonak International Adult Conference: Hearing care for adults 2009 - The challenge of aging. Phonak AG, Staefa, Switzerland, 191-202.

Liu, C-F., Collins, M.P., Souza, P.E., Yueh, B. 2011. Long-term costeffectiveness of screening strategies for hearing loss. J Rehabil Res Dev 48:235-244.

Nachtegaal, J., Smit, J.H., Smits, C., Bezemer, P.D., van Beek, J.H, Festen, J.M., Kramer, S.E. 2009. The association between hearing status and psychosocial health before the age of 70 years: results from an internet-based national survey on hearing. Ear Hear, 30:302-312.

Paglialonga A., Tognola G., Grandori F. 2011. SUN-test (Speech Understanding in Noise): a method for hearing disability screening. Audiology Research 1:e13.
Pichora-Fuller, MK., Singh, G. 2006. Effects of age on auditory and cognitive processing: implications for hearing aid fitting and audiologic rehabilitation. Trends Amplif 10:29-59.

Popelka, M.M., Cruickshanks, K.J., Wiley, T.L., Tweed, T.S., Klein, B.E., Klein, R. 1998. Low prevalence of hearing aid use among older adults with hearing loss: the Epidemiology of Hearing Loss Study. J Am Geriatr Soc., 46:075-8.

Schneider, B.A., Pichora-Fuller, M.K., Daneman, M. Effects of senescent changes in audition and cognition on spoken language comprehension. In: Gordon-Salant S, Frisina, RD, Popper AN, Fay RR (eds.). The aging auditory system. Springer, New York, USA, 2010;167-210.

Smits, C., Houtgast, T. 2005. Results from the Dutch speech-in-noise screening test by telephone. Ear Hear 26:89-95.

Sułkowski, W.J., Sward-Matyja, M., Matyja, W. 2001. AUDIOBUS--the first Polish audiological mobile unit. Int J Occup Med Environ Health 14:79-80.

Thodi, C., Parazzini M., Kramer S.E., Davis A., Stenfelt S., Janssen T., Stephens D., Smith P., Pronk M., Anteunis L.J., Grandori F. 2011. Adult hearing screening: the Cyprus Pilot Program. Audiology Research 1:e18.

US Congress. 1987. Numeric designation of hearing impairment. Federal Register 52:44120.

Ventry, I.M., Weinstein, B.E. 1983. Identification of elderly people with hearing problems. ASHA 25:37-42.

World Health Organization. 2008. Grades of hearing impairment. Available at: http://www.who.int/pbd/deafness/hearing_impairment_grades/en/

Yueh, B., Collins, M.P., Souza, P.E., Boyko, E.J., Loovis, C.F., Heagerty, P.J., Liu, C.F., Hedrick, S.C. 2010. Long-term effectiveness of screening for hearing loss: the Screening for Auditory Impairment-Which Hearing Assessment Test (SAI-WHAT) randomized trial. J Am Geriatr Soc 58:427-434. 